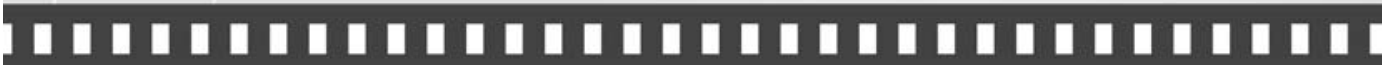 A percepção ambiental urbana com uso de imagens fotográficas: um instrumento semiótico denominado Jogo da Percepção

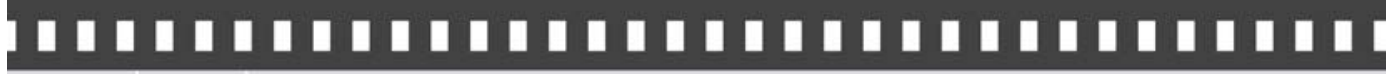

Carlos Alberto Mucelin

Luzia Marta Bellini 


\title{
A percepção ambiental urbana com uso de imagens fotográficas: um instrumento semiótico denominado Jogo da Percepção
}

The urban environmental perception with use of photographic images: a semiotic instrument named Game of the Perception

\author{
Carlos Alberto Mucelin* \\ Luzia Marta Bellini**
}

\begin{abstract}
Resumo: Este artigo sobre percepção sígnica ambiental urbana foi desenvolvido na cidade de Medianeira, Sudoeste do Paraná - Brasil. Parte das informações perceptivas dos atores sociais locais foi obtida por meio da análise de imagens fotográficas com o uso de um novo instrumento de investigação que denominamos Jogo da Percepção. A atividade do Jogo estimulou os atores sociais participantes a observar o contexto do ambiente local e ajuizar perceptivamente costumes e hábitos da população da cidade bem como vivenciar situações de estranhamento sobre práticas vigentes no uso do ambiente.
\end{abstract}

Palavras-chave: percepção, semiótica, ambiente urbano, imagem.

\begin{abstract}
This article about signs of urban environmental perception was developed in the city of Medianeira, Southwestern Paraná Brazil. Part of perceptive information of local social actors was obtained by means of analysis of photographic images with the use of a new investigation instrument that we named Game of the Perception. The activity of the Game encouraged the participating social actors to observe the context of the local environment and perceptually judge practices and habits of the city population, and also experience odd situations on effective practices and use of the environment.
\end{abstract}

Key-words: perception, semiotic, urban environmental, image.

*Prof. Dr. da Universidade Tecnológica Federal do Paraná - UTFPR. e-mail: mucelin@utfpr.edu.br. ***Prof ${ }^{a}$. Dra . da Universidade Estadual de Maringá - UEM - e-mail: martabellini@uol.com.br. 


\section{Introdução}

A cidade é um ecossistema de difícil definição dada a multiplicidade de fragmentos e condições ambientais que a contextualiza. Podemos pensar as características de seu contexto, especialmente os fragmentos habituais, como um emaranhado de signos expressos em um intricado processo fenomenológico semiótico. Também, como um fragmento ambiental humanístico, uma área geográfica que atende as intenções do ser humano, edificada onde e como ele deseja, refletindo a cultura, as crenças, as formas de uso e os hábitos dos habitantes do lugar.

Resultado do esforço e da produção cultural dos povos, a cidade se apresenta como um mosaico de possibilidades perceptivas que expressa ao mesmo tempo características gerais e particulares. Pensar a cidade também é pensar a construção humana, uma intervenção ou arte temporal e espacial delimitada, que necessariamente implica no não urbano. Aleitura perceptiva do ambiente somente pode ser levada a efeito através de signos engendrados na mente, pela percepção e legibilidade ambiental.

As percepções da cidade pelos atores sociais geram imagens múltiplas e subjetivas, por meio das quais a imagem que cada cidadão faz empurra-o a estabelecer uma intrincada teia de relações multifacetadas. Para Lynch (1999, p.3) a legibilidade não é o único atributo importante de uma cidade e lembra que “[...] devemos levar em consideração não apenas a cidade como uma coisa em si, mas a cidade do modo como a percebem seus habitantes".

Neste artigo, apresentamos parte de uma investigação ${ }^{1}$ de percepção ambiental realizada com os atores sociais da cidade de Medianeira, projetada em 1949. É uma pequena cidade de estado do Paraná, Brasil. Segundo o IBGE (2006), no ano de 2004 o município de Medianeira -

\footnotetext{
${ }^{1}$ Essa investigação é a execução do projeto de Tese intitulado "Estudo ecológico de fragmentos ambientais urbanos: percepção sígnica e pesquisa participante”. Essa pesquisa foi realizada no Programa de Pós-Graduação em Ecologia de Ambientes Aquáticos Continentais da Universidade Estadual de Maringá - UEM, sob a orientação da Prof. Dra . Luzia Marta Bellini.
} 
território municipal de $329 \mathrm{Km}^{2}$ - apresentava uma população estimada de 39,6 mil habitantes; 33,2 mil na área urbana.

Durante a fase de preparação, testes e aprimoramento dos instrumentos e técnicas da pesquisa observamos que as percepções do contexto urbano da cidade apresentada pelos atores sociais locais, eram, muitas vezes, ofuscadas pelas suas atividades habituais cotidianas, tal como registrou Ferrara (1999a) em seus estudos. As fotografias de determinados fragmentos urbanos ou situações que retratavam costumes e hábitos locais causavam estranhamento e estimulavam reflexões perceptivas sobre seu ambiente.

A utilização das imagens para investigar a percepção de determinados fragmentos desse contexto urbano nos levou a desenvolver uma técnica de investigação baseada em imagens fotográficas que denominamos Jogo da Percepção. Neste artigo apresentamos este instrumento bem como alguns resultados obtidos. Começamos pela teoria Semiótica que fundamentou nossa investigação.

\section{Considerações teóricas}

Fundamentamos nossa investigação sígnica perceptiva sobre o ecossistema urbano estudado na Semiótica de Charles Sanders Peirce. Semiótica - palavra grega semeiotiké - para Peirce (2003, p.45) equivale à lógica. Ele a considerou como “[...] a quase-necessária, ou formal, doutrinas dos signos”. Peirce (1974, p.151) definiu semiótica como “[...] a disciplina da natureza essencial e das variedades fundamentais de toda possível semiose”. (CP: 5.488) ${ }^{2}$. Para Peirce a Semiótica fundamenta as possíveis e ilimitadas semioses engendradas na mente de um intérprete através dos signos. Por sua vez, semiose é um processo que Peirce (1974, 150) definiu como “[...] uma ação ou influência que consiste em, ou envolve a cooperação de três sujeitos, o signo, o objeto e o

${ }^{2}$ Usaremos CP para designar Collected Papers e os números indicam o volume seguindo-se os parágrafos. 
interpretante, influência tri-relativa essa que não pode de forma alguma ser resolvida em ação de pares” (CP, 5.484).

Todo fenômeno, objeto ou coisa que se apresenta a um intérprete somente pode ser experienciado, percebido, através de signos. $\mathrm{O}$ signo ou representâmen foi definido por Peirce (2003, p.46-7) como “[...] aquilo que, sob certo aspecto ou modo, representa algo para alguém [...] para que algo possa ser um Signo, esse algo deve 'representar', como costumamos dizer, alguma outra coisa chamada seu Objeto” (CP 2.228; 230). O modelo de signo ${ }^{3}$ proposto por Peirce é triádico: Objeto, Interpretante e Signo ou Representâmen.

Peirce ponderou a complexidade na descrição dos fatos do mundo real e construiu sua teoria sob o pressuposto de que todo e qualquer fato deva ser vinculado a um signo dinâmico. A teoria peirceana foi, então, elaborada em três categorias fenomenológicas: primeiridade, secundidade e terceiridade. Queiroz (2004) menciona que:

[...] a categorialogia de Peirce prova que uma lista de elementos categorias cenopitagóricas - é completa; que seus constituintes, a saber, primeiridade, secundidade, terceiridade, são irredutíveis [...] que três categorias são necessárias e suficientes para explicar toda a variedade de fenômenos observados na mente.

Com base nas explicações de Peirce para a caracterização de suas categorias, Ibri (1992, p.15) afirma que "parece ser lícito inferir que o curso temporal da experiência como resultado cognitivo de viver, traduzse na aquisição de terceiridade [...]”. Segundo Ibri (1992), parece que a experiência ocorrida em nível de primeiridade e secundidade institui um vetor voltado à terceiridade, cuja força incita o "fazer pensar que” e se mostra como representações gerais compondo o pensamento mediativo, representação. Logo, na terceiridade ocorre a construção cognitiva do sujeito por intermédio da percepção.

\footnotetext{
${ }^{3}$ Apesar da importância dos signos, especialmente as tricotomias elaboradas por Peirce, não aprofundaremos discussões a respeito por não ser este o propósito deste artigo. Limitar-nosemos a semiótica de Peirce de modo geral.
} 
A primeiridade é o primeiro contato com a coisa ou fato, o presente imediato, neófito, primitivo e espontâneo, sem que a consciência tenha tempo hábil de acordar ou sentir estranhamento. Trata-se do primeiro momento das etapas que constitui a percepção, sem ser percepção, restrito à condição de sensação instantânea, e seletiva como fragmento. Para Peirce (1974, p.31), "a Categoria Primeiro é a idéia daquilo que é independente de algo mais. Quer dizer, é uma Qualidade de sensação” (CP, 5.66).

Segundo Peirce (1974, p.31), a “Categoria-Segundo é a idéia daquilo que é, como segundo para algum primeiro, independente de algo mais, em particular, independente de Lei, embora podendo ser conforme uma Lei.” Em outras palavras, é a Reação que se estabelece como um elemento do Fenômeno. A consideração de Peirce, sobre o momento de secundidade ser independente de Lei, é explicada atribuindo à Lei a essência na categoria da terceiridade, entretanto, ela não é exclusiva nessa categoria.

É na categoria fenomenológica de secundidade que ocorre a manipulação dos signos e observação dos objetos, gerando no mundo interior do sujeito a relação de binaridade. Logo, pela binaridade, primeiridade e secundidade, o ser humano é compelido a reagir e pensar de forma diferente. Para Santaella (2004, p.7), “a secundidade está ligada às idéias de dependência, de determinação, dualidade, ação e reação, aqui e agora, conflito, surpresa, dúvida”.

As modalidades fenomenológicas de Peirce se constituem em categorias universais do pensamento e da natureza, abarcando todas as experiências, sendo elucidada, como já dissemos, por meio do signo dinâmico. Sobre a terceiridade Peirce (1974, p.31) discorre que “[...] é a Idéia daquilo que faz de Terceiro, ou Medium entre um segundo e seu Primeiro. Quer dizer, é Representação de um elemento do Fenômeno” (CP, 5.66). A terceiridade ou mediação ocorre via percepção ${ }^{4}$.

\footnotetext{
${ }^{4} \mathrm{~A}$ Percepção é uma palavra de origem latina perceptione, que pode ser entendida como tomada de consciência de forma nítida sobre qualquer objeto ou circunstância. A circunstância em questão diz respeito ao fenômeno e, portanto, à fenomenologia. Peirce (1974, p. 111) denomina fenômeno tudo aquilo que "[...] esteja perante nosso espírito em algum sentido. As três categorias são as três espécies de elementos que a percepção atenta pode decifrar no fenômeno”.
} 
A percepção é, para Peirce, o objeto de estudo da semiótica que ocorre dialeticamente segundo um modelo triádico constituído de: Percepto, Percipuum e Julgamento Perceptivo (CP 7.642-643 de 1903). Peirce considerou os constituintes da percepção como entes interdependentes e indecomponíveis que permitem que se analise e caracterize isoladamente cada um deles. Assim, em toda percepção existem os elementos: o percepto ou objeto, verdadeira coisa em si mesma, que independe daquilo que dele se possa pensar, devido à sua existência e insistência sobre os sentidos sem nada manifestar; o percipuum ou o modo como o percepto, captado pelos órgãos sensoriais, é imediatamente interpretado no julgamento de percepção; é o julgamento de percepção, que corresponde a uma espécie de proposição a nos informar sobre aquilo que está sendo percebido.

A percepção de um objeto ou fato, segundo Peirce, ocorre de forma pragmática pela vivência de fenômenos que ele denominou experiência que significa o próprio ato de viver. A observação de uma imagem fotográfica, por exemplo, estimula o Percepto que estimula a mente do interprete a realizar reflexões sobre o objeto ou fato observado na imagem, culminando com o Juízo perceptivo.

\section{Imagem e fotografia}

Na investigação de percepção ambiental urbana a imagem fotográfica pode ser utilizada como um instrumento fundamental, por permitir o registro espacial e temporal do ambiente estudado, situações de uso e hábitos cotidianos além de fragmentos de seus constituintes. A fotografia marca, registra situações de fatos e fragmentos de um contexto congelando fenômenos temporal e espacialmente. Chamarelli Filho (2005) considera que a fotografia "é uma percepção do espaço-tempo. Um espaço-tempo de singularidades, margem singular de busca entre o perceber e o percebido". 
Vivemos hoje a era da fotografia instantânea, da máquina digital. Peirce (2003, p.65) considerava as fotografias ${ }^{5}$, de forma especial às instantâneas instrutivas, pois

[...] sob certos aspectos são exatamente como os objetos que as representam. Esta semelhança, porém, se deve ao fato de terem sido produzidas em circunstâncias tais que foram fisicamente forçadas a corresponder ponto por ponto à natureza.

As fotografias, mesmo sendo recortes de objetos ou paisagem e correspondendo aos pontos da natureza, do real, associando-se ainda os filtros da percepção, geralmente induzem à formação de idéias que não contemplam todos os aspectos da realidade dos fatos. Para nós, a leitura das imagens é construída segundo diversos fatores, como as ferramentas cognitivas, filtro cultural, individual, motivação, religião, crenças, costumes e hábitos, desejos, sonhos, entre outros, que influenciam na construção da realidade, da imagem mental.

A palavra fotografia induz, na maioria das vezes, a pensar de forma sígnica, na reprodução fiel de um objeto ou paisagem. Mas, afinal, o que é uma fotografia? Kubrusly (2003) lembra que definir fotografia não é uma tarefa fácil, e que pesquisando centenas de pessoas, inclusive fotógrafos, não obteve sequer uma definição igual a outra.

Kubrusly (2003, p.8-9), ao abordar o significado da fotografia, questiona sua natureza:

\begin{abstract}
A possibilidade de parar o tempo, retendo para sempre uma imagem que jamais se repetirá? Um processo capaz de gravar e reproduzir com perfeição imagens de tudo que nos cerca? Um documento histórico, prova irrefutável de uma verdade qualquer? [...] uma ilusão de ótica que engana nossos olhos e nosso cérebro com uma porção de manchas sobre o papel, deixando uma sensação tão viva de que estamos diante da própria realidade retratada?
\end{abstract}

\footnotetext{
${ }^{5}$ Segundo Kubrusly (2003), a primeira fotografia data de 1827, feita na França. A partir de 1841, com a produção de chapas mais sensíveis e objetivas mais luminosas, associados ao aprimoramento do processamento químico, tornou-se possível o retrato.
} 
A resposta sobre tais questionamentos é afirmativa tanto para Kubrusly como para nós.

Segundo Chamarelli Filho (2005), a fotografia

[...] é um método, com o qual se observa a realidade [...] a foto reage de maneira reflexiva ao procurar ser fabular, ser, um intervalo perceptivo de uma realidade, como generalidade dos (aos) acontecimentos e do olhar habitual dos fatos.

É nesse pressuposto da imagem fotográfica, de permitir a alguém observar recortes fixados da realidade, da percepção habitual dos fatos, que imputamos à fotografia o crédito de ser um instrumento facilitador do estudo da percepção ambiental. Como ícone, a fotografia permite a um observador ler circunstâncias de um contexto, permitindo que a realidade ou fragmento se revele de maneira tão corriqueira que pode ser pensada como significante, ou elemento revelador da realidade.

A imagem registrada em uma fotografia jamais se repetirá na totalidade, inclusive os fenômenos a ela vinculados. Nem mesmo quando tal registro ocorre numa circunstância fenomenológica próxima aos ditames de uma lei, a repetição do fato será sempre uma aproximação, com maior ou menor qualidade, intensidade e quantidade de detalhes, dependendo não somente do fenômeno em si, mas da percepção do observador, que também é dinâmica. Entretanto, é possível perceber através das imagens certas regularidades, comportamentos que podem ser pensados como lei, ou como força do hábito, e que nos interessa enquanto objeto de estudo.

Para Addison (2003, p.2), a expressão “imagem” sugere “[...] um tipo de objeto resultante da relação entre o meio e o homem em um estrito senso de espontaneidade”. Addisson lembra que para elucidar as imagens e compará-las com situações reais “[...] usamos, freqüentemente, os mapas mentais, sendo que esses são componentes de um processo que resulta na expressão de objetos percebidos, os quais são as expressões da relação do sujeito com o meio urbano”. 
Expósito (2005) considera que a imagem primeiramente: “evidencia o caráter incompleto de nossa percepção, deixando aparecer uma ausência ou uma perturbação. [...] Aparece assim, de novo, o processo de estranhamento, que nos faz distanciar daquilo que vemos". A fotografia é um instrumento sígnico perceptivo, que tem a potencialidade de expressar situações de singularidade de hábitos.

Em nossa pesquisa preconizamos o registro fotográfico de determinados ambientes urbanos ao longo do tempo de investigação. Registramos imagens de constituintes do ecossistema urbano pesquisado: fundos de vale, margens e leito dos rios, áreas centrais e nobres; o ambiente lixão da cidade e os catadores em atividade nesse local. Com o uso das fotografias procuramos fixar situações cotidianas dos fragmentos e situações habituais no contexto da cidade de Medianeira. Depois de diversos ensaios com imagens e entrevistas, desenvolvemos uma técnica de investigação qualitativa que batizamos de Jogo da Percepção.

\section{O Jogo da Percepção}

Por ser uma modalidade de pesquisa que investiga considerações sobre a experiência vivenciada, um estudo de percepção ambiental pressupõe a utilização de um rigor metodológico construído com criatividade, sem ficar condicionado, necessariamente, à adoção de um modelo teórico, método ou técnica prefixada. Para Ferrara (1999b, p.66), no estudo de percepção ambiental, “[...] cada pesquisa é uma e única testando, na singularidade, hipóteses, metodologias e técnicas”.

Na paisagem urbana de Medianeira as situações ambientais acenavam para crenças e hábitos da população local, que podiam ser registradas pela fotografia, facilitando o estudo e a caracterização da percepção ambiental dos atores investigados. 
Durante a fase de aprimoramento e testes dos instrumentos de investigação para a definição do roteiro de entrevista com o uso de imagens, percebemos o poder sígnico da fotografia nas pessoas que entrevistamos, quanto à sua percepção do ambiente urbano. Isso nos levou a construir o Jogo da Percepção.

Denominamos “Jogo de Percepção” a atividade de análise perceptiva realizada com um conjunto de imagens previamente escolhidas sobre um determinado tema ou objeto de estudo. Essas imagens pressupõem registrar situações de contraste ou dualidade dentro do objeto de estudo, para que possam estimular e evidenciar a percepção do participante do jogo (ator social) sobre a temática.

A idéia central desse instrumento de investigação é confrontar situações de contraste sígnico perceptivo dentro do objeto de estudo. No nosso caso, por exemplo, apresentamos aos participantes imagens que retratavam situações de um ambiente limpo, bem cuidado geralmente, pertencente às áreas nobres da cidade que se contrapunham com outros ambientes como os fundos de vale e cercanias. Nestes, evidências de maus tratos e com visíveis costumes e hábitos de disposição inadequada de lixo, poluição, contaminação, descaso.

Depois de acordada a participação do ator social, o Jogo da Percepção pode ser planejado para acontecer segundo os momentos:

\section{- Momento 1}

Entregar as fotografias embaralhadas e solicitar que sejam observadas.

- Questionar sobre o que elas retratam: visa evidenciar a percepção do participante sobre o objeto de estudo

- Questionar sobre o local das imagens: pretende evidenciar a identificação do participante sobre o local investigado.

\section{- Momento 2}

Perguntar se todas as imagens retratam o local que o investigador está pesquisando. Caso uma ou mais imagens não sejam percebidas como 
do local da investigação, solicitar que sejam separadas. Isso pode evidenciar a percepção ou conhecimento do participante sobre o local investigado, a ser analisado posteriormente.

\section{- Momento 3:}

Solicitar ao participante que separe as imagens segundo os contrastes já preconizados pelo pesquisador. Pedir que o participante organize as fotografias em tantos grupos quanto julgar pertinente sobre a temática investigada.

Neste momento do jogo, finalizada a organização dos grupos de imagens, perguntar ao participante primeiro sobre um dos lados do contraste investigado (aqui é importante que os diálogos sejam gravados para posterior registro e análise).

- Quantos grupos organizou?

- Como denomina cada grupo?

- Com as fotografias já numeradas no verso para não influenciar o participante, indagar: o que cada grupo significa, o que retratam, porque ocorrem, se aquelas imagens retratam situações visíveis no lugar da investigação, de quem é a responsabilidade, etc.

Nota: É muito importante que cada grupo de imagens seja registrado (anotar os números das fotografias agrupadas. A numeração deve ser previamente realizada no verso) pelo pesquisador em uma ficha, para confrontar quando das análises dos resultados, quais imagens retratam a percepção do ator entrevistado. Isso contribui para evidenciar a percepção ambiental individual e coletiva.

\section{- Momento 4:}

Conversar sobre o grupo ou grupos de imagens opostas às situações investigadas no momento 3 , repetindo os questionamentos, ou seja:

- Quantos grupos organizou nesta situação (ou simplesmente anotar)?

- Como denomina o grupo, ou cada grupo? 
- Registrar o número do verso das fotografias e indagar: o que o grupo significa, o que retratam, porque ocorrem, se aquelas imagens retratam situações visíveis no lugar da investigação, de quem é a responsabilidade, etc.

Em nosso estudo, registramos aproximadamente 3000 imagens fotográficas do ambiente urbano de Medianeira durante 12 meses, a partir de maio de 2005. Como previsto nos procedimentos metodológicos da pesquisa, a atividade do Jogo foi realizada ao final das entrevistas ${ }^{6}$ com os atores sociais investigados. Como estratégia investigativa, utilizamos uma ficha para registrar as reações do entrevistado e o número das imagens escolhidas segundo seus significados perceptivos. Também gravamos os diálogos dessa atividade e os digitamos na íntegra, para posterior análise.

Dos registros fotográficos que tínhamos, escolhemos 45 imagens de locais do ambiente urbano de Medianeira, com fotografias reveladas nas dimensões 15x21cm que compuseram o nosso Jogo. As imagens contemplaram fragmentos habituais locais da cidade: o leito do rio Alegria, o ambiente lixão, as áreas limítrofes da cidade com a área rural, os lotes baldios, as edificações nobres, as edificações de bairros pobres, os monturos a céu aberto, a praça central, as igrejas, os jardins, as avenidas, as ruas sem pavimentação, o lixo hospitalar depositado a céu aberto, as áreas centrais, os bairros nobres, os bairros pobres e os fundos de vale.

O Jogo da Percepção é fundamentalmente um instrumento focado no efeito da imagem. Pressupomos que as fotografias escolhidas para o jogo estimulassem a reflexão sobre os fenômenos culturais que engendram a percepção ambiental, individual e coletiva da comunidade investigada.

\footnotetext{
${ }^{6}$ Foram realizadas 88 entrevistas e 88 atividades do Jogo com atores de 11 atividades profissionais. Foram investigados 8 atores sociais para cada atividade, 4 do sexo masculino e 4 do feminino: funcionários do comércio; proprietários de comércios do centro; dentistas; médicos; proprietários de comércios de bairros; professores universitários; professores do ensino médio; alunos universitários; políticos; donas de casa do centro; e donas de casa de bairros. Com as imagens, os participantes puderam analisar os recortes do ambiente urbano de Medianeira, avaliar e enunciar como os percebiam.
} 


\section{Alguns resultados perceptivos obtidos com o Jogo da Percepção}

O Jogo da Percepção foi estruturado para ser um instrumento estimulador da percepção, retratando contrastes diversos objetivando permitir ao ator "jogador” a reflexão mediada pela potencialidade sígnica das imagens. Isto porque a imagem fotográfica, como lembra Santaella (2004, p.102); “[...] é um instantâneo congelado para sempre”. Registra espacial e temporalmente e tem o poder de acrescentar e sugerir ao intérprete, situações que significam a mensagem a ser mediada, aguçando a percepção por um conjunto de impressões sígnicas.

Iniciávamos a atividade do Jogo da Percepção entregando 45 imagens fotográficas ${ }^{7}$ coloridas. Informávamos aos participantes que as imagens eram recortes de um ambiente urbano e solicitávamos que eles primeiramente olhassem todas elas e, depois, conversaríamos sobre suas representações e os significados.

Observamos e registramos que, durante a primeira visualização das imagens, aquelas que retratavam a disposição inadequada de lixo em rios, fundos de vale, monturos em lotes baldios e ruas e o ambiente lixão, causavam estranhamento e aversão, expressos corporal e verbalmente. Enquanto olhavam as fotografias, as expressões que mais ouvimos foram “Meu Deus do céu!” e "Nossa senhora, o que é isso!”. Estas expressões evidenciaram o estranhamento dos atores de situações habituais no contexto da cidade investigada, mas que eram mascaradas pelas atividades cotidianas, apresentadas por meio do discurso religioso. Apresentamos como exemplo algumas dessas argumentações: “Eu achava que o lixo hospitalar não era jogado no lixão!”; “As pessoas não imaginam que estes lugares existem!” (Trabalhadora do comércio

\footnotetext{
${ }^{7}$ As imagens do Jogo da Percepção estão disponíveis no ícone Arquivos da página do Prof. Carlos: $<$ http://www.md.cefetpr.br/Intranet/professores/index.php?idusuario=41>.
} 
E7). "Vixe Maria, quanto lixo!”; “Meu Deus do céu, que tristeza!” (Dona de casa do centro E7).

Depois que os atores olhavam as imagens, perguntávamos a eles o que significavam. Em todos os grupos de profissionais investigados os atores perceberam e interpretaram as imagens fotográficas com uma dualidade sígnica. De um lado, imagens que retratavam aquilo que eles consideravam como bom e agradável, e de outro, situações negativas, desagradáveis, como a falta de manutenção e zelo em determinados ambientes e dos hábitos indevidos de disposição inadequada do lixo. A dualidade percebida nas imagens estimulava a reflexão sobre os ambientes fotografados e, conseqüentemente, o juízo perceptivo viabilizado pelas cenas observadas, pois contrastavam ou se alinhavam com algumas crenças locais instituídas.

Nos diálogos dos atores, depois de contempladas as imagens, observamos que, de imediato, a atividade do Jogo estimulava a superação do contínuo homogêneo dos hábitos instituídos e de suas percepções sobre o contexto da cidade. Em outras palavras, as imagens do Jogo da Percepção permitiam ressaltar igualdades e perceber contradições antes obscurecidas pelos hábitos locais instituídos. Ao contemplar as imagens uma dentista disse: "Mostram a cidade com dificuldade. Imagens bonitas que parecem cartões postais, realmente centro bonito em contraste com os bairros, pobreza, falta de equilíbrio natural. As imagens descreveram tudo" (Dentista E6).

Os argumentos de um professor, ao interpretar as imagens, acenam para o estranhamento e a observação dos fragmentos habituais locais que não eram para ele corriqueiramente percebidos: "Mostra que tem muito lixo, poluição na maioria e lugares bonitos. Mas ofusca! A gente não imagina que isto existe! Na verdade, não observa” (Professor do Ensino Médio E3).

Depois que registramos a percepção dos atores acerca do conjunto de fotografias, questionamos se eles sabiam em qual ambiente urbano elas haviam sido feitas. A maior parte das imagens foi percebida como parte do ecossistema urbano de Medianeira. 
Afirmávamos aos entrevistados que todas as imagens eram do ambiente urbano de Medianeira. Seguimos com a execução do Jogo, solicitando que os atores separassem as imagens em pelo menos 2 grupos, agrupando de um lado aquelas que retratavam o lado bom e belo da cidade, e de outro o lado ruim ou negativo. Feitas as separações questionávamos: "Com base nesse grupo de imagens que o senhor(a) separou, como aquelas que retratam o lado bom e belo, o que essas imagens significam?”.

Registramos que as imagens escolhidas como ícones do lado bom eram as que retratam as áreas nobres, o centro e, especialmente, aquelas que apresentavam os ambientes limpos e bem cuidados, lugares nos quais os serviços públicos de manutenção e fino trato eram evidentes, locais agradáveis e, geralmente, perceptíveis cotidianamente. As fotografias mais escolhidas com este significado retratavam as edificações nobres como a igreja e os edifícios imponentes, os jardins e monumentos da praça central. Registramos ainda que as residências pertencentes à classe média alta foram escolhidas pela maioria dos atores, independentemente das atividades profissionais, o que indica um ideal urbano, como argumenta Tuan (1980).

Os atores percebiam que o ambiente considerado por eles como bom e belo pertencia mais ao centro ou às áreas nobres. Suas percepções se alinharam aos argumentos das entrevistas que fizemos, pois observaram que o poder municipal tinha maior atenção e zelo com o centro e áreas nobres.

As 45 imagens do Jogo foram numeradas no verso. Desse modo, pudemos verificar quais foram escolhidas pelos atores como as que indicavam o lado bom da cidade, analisando o grupo de entrevistados ou por profissões investigadas. Registramos que a fotografia de número 1 do Jogo (figura 1) foi escolhida por todos os atores investigados (88) como uma imagem que representa o lado bom da cidade. 


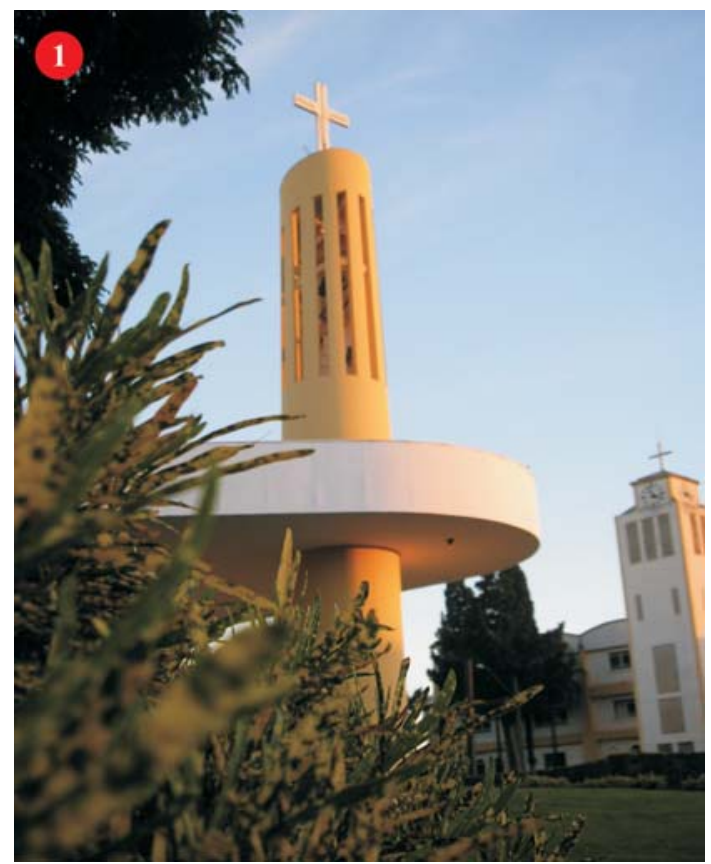

Figura 1 - Fotografia número 1 do Jogo: Igreja Matriz de Medianeira Foto: Carlos Alberto Mucelin, 2005

Esta imagem mostra a fachada frontal da igreja matriz da cidade e é o registro de um dos recortes da área mais nobre de Medianeira - o centro. Trata-se de um ambiente perceptível a todos e considerado o mais importante da cidade.

Entre os 88 atores investigados, 56 (64\%) escolheram 4 imagens, as de números 2, 14, 37 e 41 . Na figura 2 apresentamos as imagens 2 e 14, escolhidas como as que representavam o lado bom da cidade. Registramos que todos os profissionais investigados dos grupos de professores universitários, professores do ensino médio, alunos universitários, políticos, médicos e donos de casa de bairro escolheram as 4 fotografias mencionadas com este significado. Essas imagens sugerem que os atores percebem como lado bom da cidade o ideal urbano de moradia e as áreas centrais e nobres. A imagem 1 da figura 2 indica o padrão de moradias percebido como ideal e simbolizam o sonho de propriedade urbano (status). 

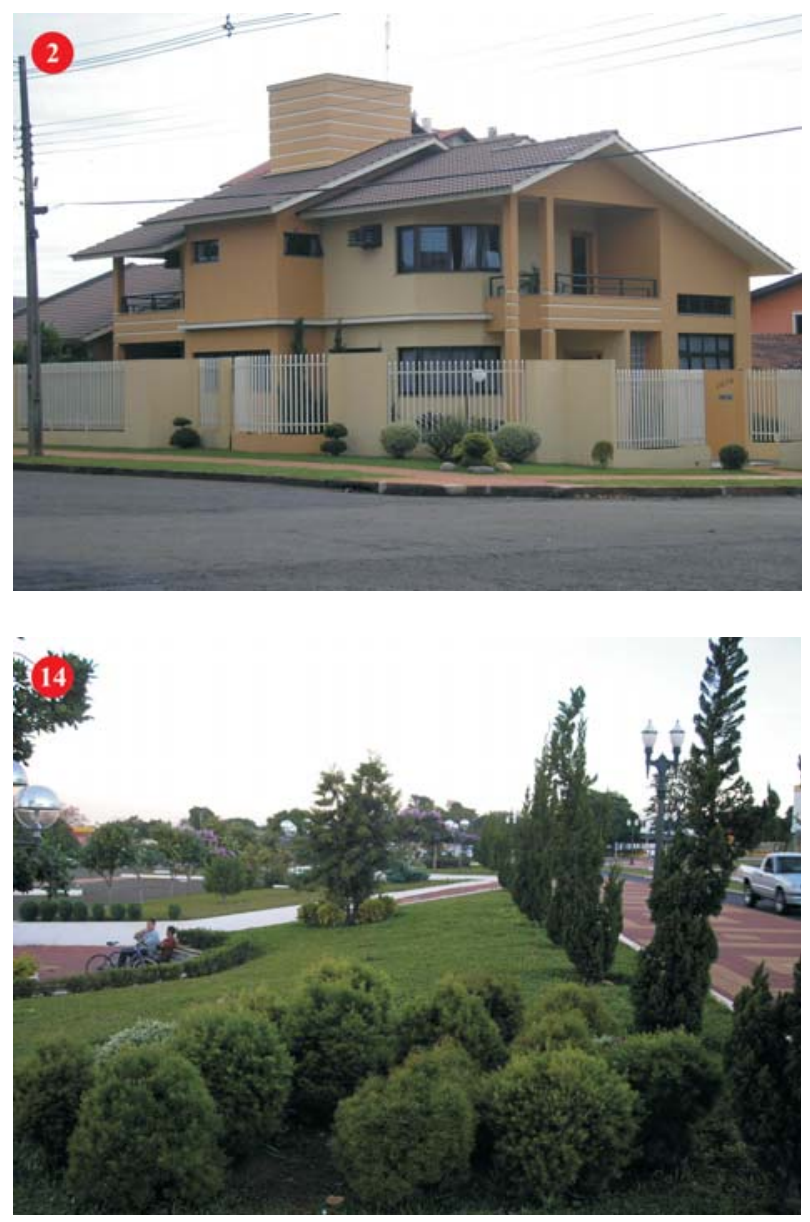

Figura 2 - Duas das 4 Imagens escolhidas pela totalidade dos atores de 6 grupos pesquisados Fotos: Carlos Alberto Mucelin, 2005

Isso se alinha ao que Tuan (1980, p.254) tipifica como lar na concepção da classe média: "tipicamente composta de uma casa rodeada de gramado e separada do mundo público das ruas”. Esta tipificação é visível no ambiente urbano de Medianeira, especialmente nos bairros nobres de classe média e alta. Na imagem 14 da figura 2, o jardim da Praça Ângelo Da Rol percebido como ambiente nobre, bem cuidado, lugar de zelo, agradável. 
As fotografias 6, 44 e 45 (figura 3) foram lembradas por todos os integrantes dos grupos de médicos e donos de casa de bairros. Analisando as informações dos 11 grupos investigados (88 atores), apenas os dentistas não escolheram nenhuma dessas 3 fotografias para representar o lado bom. Não obstante, nos demais grupos, ao menos uma destas imagens foi escolhida.
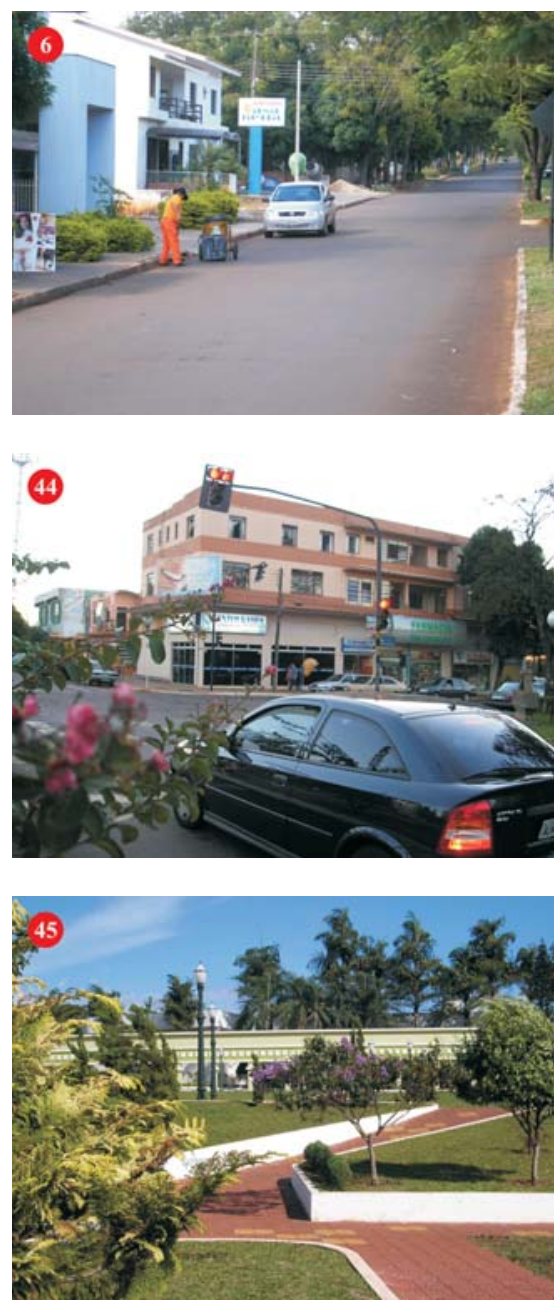

Figura 3 - Imagens escolhidas pela totalidade dos atores de 2 grupos pesquisados Fotos: Carlos Alberto Mucelin, 2005 
De modo geral, as escolhas dos atores foram sempre das áreas nobres e suas edificações como aquelas que significavam o lado bom de Medianeira. Depois de dialogar sobre as imagens do lado bom, perguntávamos aos participantes o que as imagens agrupadas como o lado ruim da cidade representavam para eles -32 fotografias foram percebidas e vinculadas ao lado negativo de Medianeira.

Analisando os diálogos dos participantes sobre o que as imagens negativas significavam, registramos como núcleo sígnico perceptivo, independentemente da atividade profissional, que essas imagens eram condenáveis, especialmente pelas agressões ao ambiente. Os atores reagiram com repúdio aos hábitos de tratamento e disposição inadequada de lixo, as condições do ambiente lixão, à pobreza e à exclusão social dos catadores de recicláveis e os visíveis impactos negativos aos rios locais como o lançamento de lixo e esgoto in natura.

Uma vez que todos repudiavam o que as imagens negativas significavam, organizamos suas considerações em 3 núcleos perceptivos: o contexto do lixão; os rios maltratados; e os hábitos de tratamento e disposição inadequados de lixo.

Os hábitos inadequados de tratamento e disposição final do lixo doméstico da cidade ocorrem em praticamente todo o contexto urbano, inclusive na região central. Inserimos na figura 4 três das 9 imagens ( 7 , $8,16,17,18,22,23,24,25)$ que retratam sinais e circunstâncias destes hábitos.

Imagens como as da figura 4 foram percebidas como os maus hábitos instituídos e intensos nos moradores locais. Os atores investigados afirmam que esses hábitos existem na cidade, e que alguns são quase imperceptíveis pelo cotidiano das pessoas. Quando questionamos sobre o porquê de tais hábitos ocorrerem, os atores disseram que é falta de consciência, educação, cultura. Faltava respeito com a Natureza. 

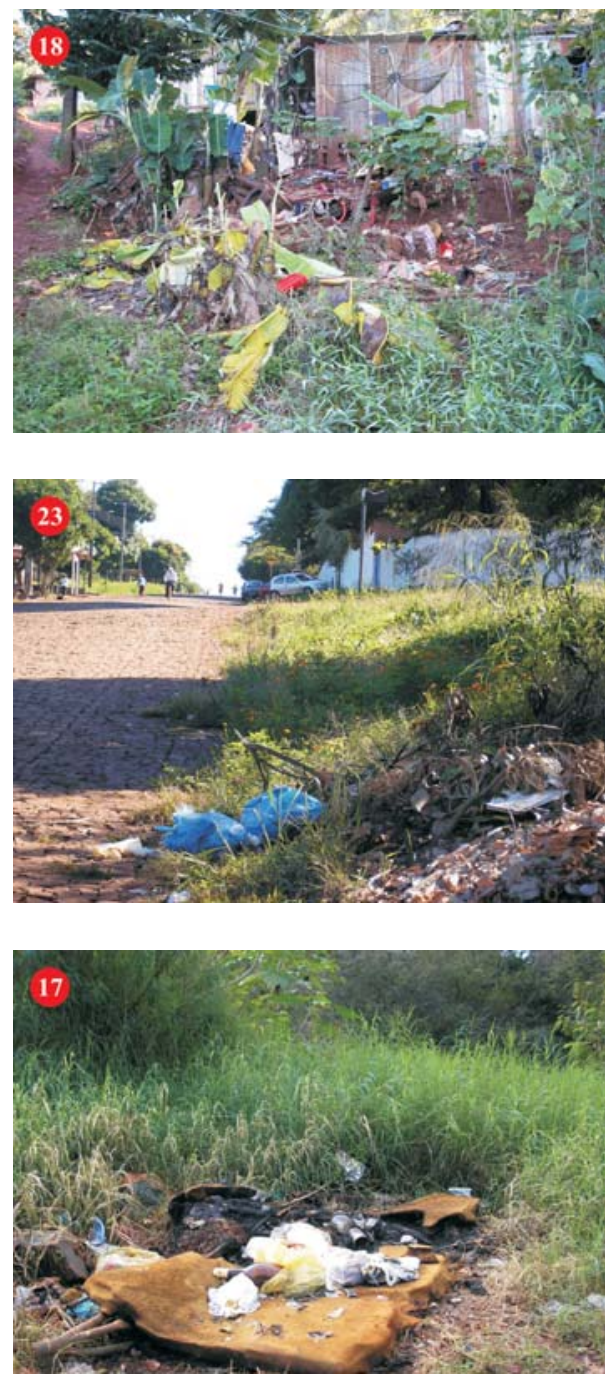

Figura 4 - Imagens que retratam o tratamento e a disposição inadequada de lixo Fotos: Carlos Alberto Mucelin, 2005

Sobre os rios maltratados, segundo núcleo perceptivo sistematizado, registramos novamente a indignação de todos os entrevistados. As imagens do rio Alegria retratam o lixo inadequadamente depositado e esgotos sendo lançados (figura 5) e caracterizam os maus tratos. 

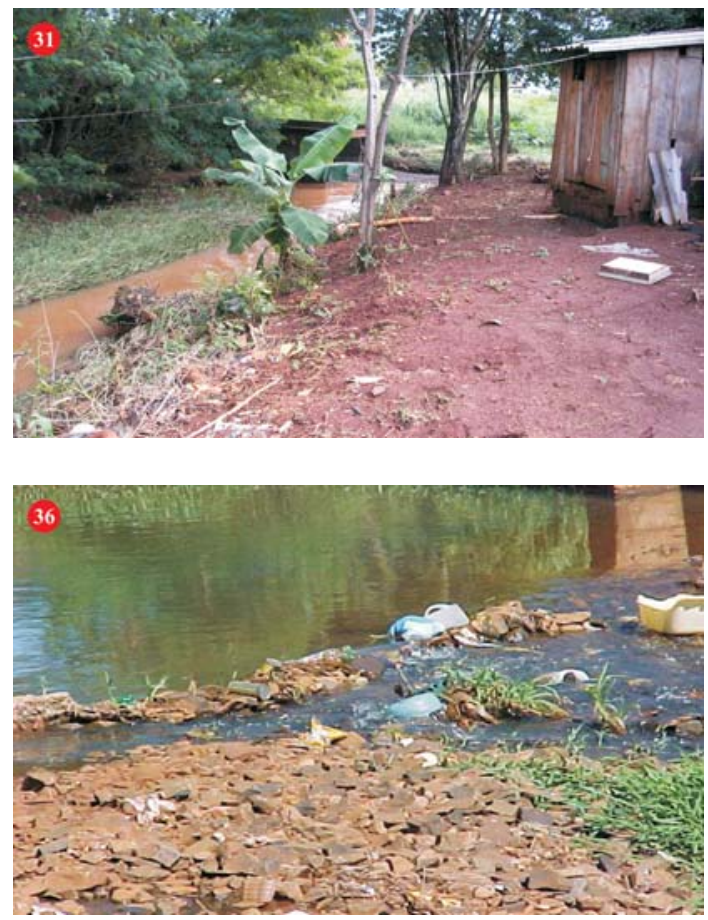

Figura 5 - Evidências icônicas dos maus tratos ao rio Alegria Fotos: Carlos Alberto Mucelin, 2005

As imagens do rio Alegria - que corta a cidade - com evidências de agressões ambientais, provocaram indignação e até revolta nos entrevistados, que não acreditavam que tais impactos eram tão intensos.

O que mais provocou estranhamento e reprovação nos atores investigados foram as imagens do lixão, terceiro núcleo sígnico perceptivo mencionado pelos atores. Muitos não conheciam este ambiente ou sequer tinham visto alguma imagem dele. No Jogo, utilizamos 12 imagens com recortes desse contexto ambiental, retratando desde os diferentes tipos de resíduos tais como o lixo hospitalar, vetores como as moscas, os gases expelidos e os catadores de reciclagem em atividade nesse ambiente. A figura 6 traz as imagens 27 e 43 do Jogo da Percepção. 

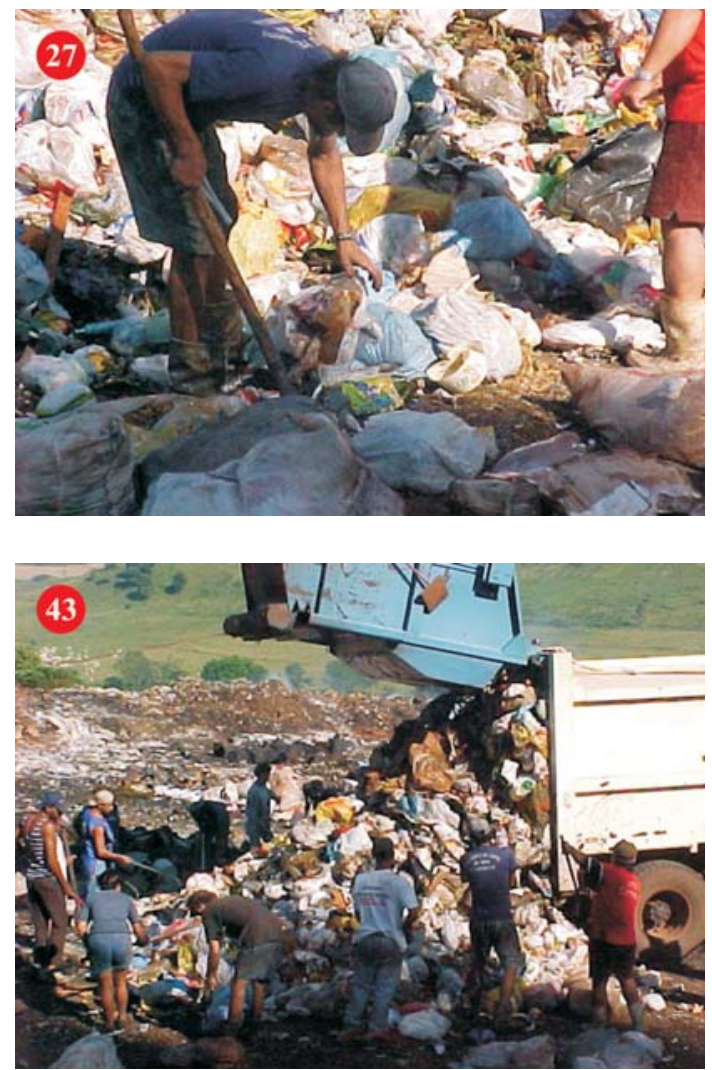

Figura 6 - O contexto do lixão de Medianeira Fotos: Carlos Alberto Mucelin, 2005

O ambiente lixão de Medianeira é totalmente topofóbico e percebido pelos atores investigados como tal. A percepção desse ambiente como desagradável e ruim, remete às considerações de Flores (2005, p.101) quando comparou os termos topofilia e topocídio, afirmando que:

[...] topocídio está relacionado com interesses estranhos ao lugar, ou a um desequilíbrio de interesses, internos e externos, que acaba ocasionando sua inviabilização como lugar, desvalorização ou mesmo destruição. 
Os atores disseram que os hábitos existem e muitos deles não são percebidos por estarem à margem do contexto das atividades cotidianas. No que diz respeito à responsabilidade consideram: de um lado o cidadão, que não possui hábitos adequados de tratamento e disposição final de lixo, causa sérios impactos ambientais negativos ao ecossistema urbano; de outro, a administração pública do município, que não desenvolve uma política de saneamento básico adequada.

\section{Considerações finais}

O Jogo da Percepção foi criado com o propósito de estimular os atores investigados a observar e refletir sobre determinadas situações e fragmentos do ambiente urbano de Medianeira. Também preconizou permitir a interação e leitura sígnica das imagens, por meio das quais os atores pudessem expressar suas percepções ambientais: quais as situações cotidianas lhes eram alheias, como viam os fragmentos habituais locais e como percebiam o contexto urbano local por meio das imagens do Jogo.

Observamos que a atividade do Jogo da Percepção estimulou a reflexão cognitiva dos participantes. A semiose, responsável pelo processo cognitivo humano, instituiu signos perceptivos usados na leitura do ambiente urbano local. As representações sígnicas responsáveis pelo ato cognitivo individuais ocorrem necessariamente por meio de experiências vivenciadas para passar a existir na mente humana. É o sentido pragmático defendido por Peirce e que o Jogo estimulou.

Notadamente, as imagens do Jogo associadas à percepção que os atores investigados tinham de Medianeira estimulou uma nova releitura do lugar. Ferrara (1999a) afirma que o ser humano desenvolve uma capacidade que consiste em associar imagens sobre algo, combiná-las parcial ou totalmente, sempre obedecendo a um hábito mental de associação de idéias. Observamos que essa associação de elementos 
da experiência ocorreu no contexto das categorias cenopitagóricas de Peirce, enquanto o Jogo da Percepção acontecia.

O conjunto de imagens do Jogo da Percepção possuía uma mensagem com múltiplos significados perceptivos, retratando situações intensas. As imagens estimularam os participantes a uma situação autoreflexiva dos hábitos locais e os fragmentos habituais urbanos de Medianeira, caracterizando-se por um momento de atividade de conscientização dos atores envolvidos. De um lado, as fotografias dos fragmentos da cidade constituíram um evidente registro espaço temporal da intervenção humana, caracterizando o lugar e os hábitos. De outro, o Jogo da Percepção constituiu uma obra viva e experienciada pelos participantes.

Os resultados perceptivos que obtivemos por meio do Jogo da Percepção sugerem que a imagem fotográfica potencializa a leitura ambiental de um local, fixando tempo, fatos, situações de um cotidiano, da paisagem pública ou privada, individual ou coletiva além de permitir revelar para as atuais e às novas gerações situações ou idéias de uma possível realidade.

\section{Referências}

ADDISON, Ester Eloisa. A percepção ambiental da população do município de Florianópolis em relação à cidade. Florianópolis, 2003. 152 p. Dissertação de mestrado. - Mestrado em Engenharia da Produção da Universidade Federal de Santa Catarina - UFSC,2003.

\section{CHAMARELLI FILHO, Milton. Fotografia, percepção e}

subjetividade. Disponível em: <http://www.studium.iar.unicamp.br> Acesso em: 1 jun. 2005.

EXPÓSITO, Alberto Martín. O tempo suspenso: fotografia e relato. Disponível em: <http://www.studium.iar.unicamp.br> Acesso em: 1 jun. 2005. 
FERRARA, Lucrécia D’Alessia. Olhar periférico: informação linguagem, percepção ambiental. 2. ed. São Paulo: EDUSP, 1999a.

. As cidades ilegíveis. In: RIO, Vicente Del; OLIVEIRA, Lívia de (Org.). Percepção ambiental: a experiência brasileira. 2 ed. São Paulo: Studio Nobel, 1999b. p. 61-80.

FLORES, José Antônio Vieira. Da paisagem imposta à paisagem desejada: a dimensão cultural como eixo referencial na recuperação de cenários degradados. 2005. Tese (Doutorado em Engenharia de Produção) - Universidade Federal de Santa Catarina - UFSC, Florianópolis.

IBRI, Ivo Assad. Kósmos Noetós: a arquitetura metafísica de Charles S. Peirce. São Paulo: Perspectiva: Hólon,1992.

IBGE. Medianeira. Disponível em: < http://www.Ibge.gov.br/cidades>. Acesso em: 31 ago. 2006.

KUBRUSLY, Cláudio Araújo. O que é fotografia. 4. ed. São Paulo: Brasiliense, 2003.

LYNCH, Kevin. A imagem da cidade. Tradução por Jefferson Luiz Camargo. São Paulo: Martins Fontes, 1999.

NÖTH, Wielricd Panorama da semiótica: de Platão a Peirce. 3.ed. São Paulo: Annablume, 2005.

PEIRCE, Charles Sanders. Escritos coligidos. Seleção de Armando Mora D’Oliveira. Tradução por Armando Mora D’Oliveira e Sergio Pomerangblum. São Paulo: Abril Cultural, 1974. 
PEIRCE, Charles Sanders. Semiótica. Tradução por José Teixeira Coelho Neto. 3. ed. São Paulo: Perspectiva, 2003.

QUEIROZ, João. Semiose segundo C. S. Peirce. São Paulo: EDUC, FAPESP, 2004.

SANTAELLA, Lúcia. O que é semiótica. São Paulo: Brasiliense, 2004.

TUAN, Yi-Fu. Topofilia: um estudo da percepção, atitudes e valores do meio ambiente. Tradução por Lívia de Oliveira. São Paulo/Rio de Janeiro: Difel, 1980. 
